\title{
Na cena jornalística: incitamentos à vontade de família
}

\section{In journalistic scene: incitement to the will family}

\section{En la escena periodística: incitaciones a la voluntad de familia}

\section{Luciana Rodrigues*}

Universidade Federal do Rio Grande do Sul - UFRGS, Porto Alegre, Rio Grande do Sul, Brasil

\section{Inês Hennigen**}

Universidade Federal do Rio Grande do Sul - UFRGS, Porto Alegre, Rio Grande do Sul, Brasil

\begin{abstract}
RESUMO
Este trabalho problematiza discursos midiáticos acerca de duas estratégias que operam na garantia ao direito à convivência familiar e comunitária de crianças e adolescentes: os serviços de acolhimento e a adoção. Com base em referenciais teórico-metodológicos foucaultianos e do campo do jornalismo, analisamos uma série e um programa jornalístico televisivo de modo a investigar como essas estratégias são visibilizadas. Constatamos a produção de regimes de verdade que nos convocam a olhar os sujeitos, os quais passaram pelos serviços de acolhimento, sob a ótica do abandono e da perda da infância, e mostramos como tal construção se articula e contribui para compor o incitamento a uma vontade de família. Discutimos as formas como se operam proposições de verdades no território midiático e seus efeitos subjetivos, e colocamos em questão o que se enuncia a luz da concepção foucaultiana de governamentalidade.
\end{abstract}

Palavras-chave: crianças, família, verdade, jornalismo, subjetividade.

\section{ABSTRACT}

This paper discusses media discourses about two strategies that operate guaranteeing the right to family and community life of children and adolescents: childcare services and adoption. Based on Foucault's theoretical and methodological references and on the field of journalism, we analyze a series and a television news programs in order to investigate how these strategies are visualized. We verified the production of truth that call up our look at the subject passing through the abandonment and loss of childhood services schemes, and we show how such a construction is articulated and contributes to incite a desire for family. We discuss the ways propositions of truth operates in media territory and its subjective effects, and bring into question what is enunciated in the light of Foucault's concept of governmentality.

Keywords: children, family, truth, journalism, subjectivity. 


\begin{abstract}
RESUMEN
Este documento problematiza a los discursos mediáticos sobre dos estrategias que operan en la garantía del derecho a la familia y a la vida comunitaria de niños y adolescentes: los servicios de cuidado de niños y la adopción. Con base en las referencias teóricas y metodológicas de Michel Foucault y del campo del periodismo, se analizan a una serie y a un periódico televisivo con el fin de investigar cómo se visualizan a estas estrategias. Hemos verificado a la producción de regímenes de verdad que nos hacen mirar a los sujetos que pasan por los servicios de cuidado por la óptica del abandono y de la pérdida de la infancia, y hemos mostrado cómo dicha producción articulase y contribuye a la incitación de la voluntad de la familia. Aún, discutimos también las maneras como se operan propuestas de la verdad en el territorio mediático y sus efectos subjetivos, y ponemos en cuestión lo que se enunció a la luz del concepto de gubernamentalidad de Foucault.
\end{abstract}

Palabras clave: niños, familia, la verdad, periodismo, subjetividad.

\title{
1 Um direito nas lentes da mídia jornalística televisiva: contornos de uma pesquisa
}

A proteção e defesa ao direito à convivência familiar e comunitária de crianças e adolescentes têm ganhado relevância nas políticas públicas brasileiras. Tal direito, presente na Constituição Federal de 1988 e reafirmado pelo Estatuto da Criança e do Adolescente - ECA (Brasil, 1990), parece ser uma das prioridades nas ações do Governo Federal que, em 2006, lançou o Plano Nacional de Promoção, Proteção e Defesa do Direito de Crianças e Adolescentes à Convivência Familiar e Comunitária (Brasil, 2006). Em 2009, um novo documento surgiu na tentativa de efetivar sua garantia: a Lei 12.010, conhecida como a Nova Lei de Adoção (Brasil, 2009).

Interessadas nesta questão, observamos que a temática da adoção, guardando certa sincronia com o lançamento de documentos oficiais, vinha sendo pauta na mídia. Por entendermos que a mídia constitui, hoje, um importante espaço de produção e embate de discursos que posicionam sujeitos (Foucault, 2000), desenvolvemos uma pesquisa ${ }^{1}$ com o objetivo de problematizar os discursos veiculados pelo jornalismo televisivo em torno da garantia ao referido direito no que concerne a duas estratégias à sua efetivação: os serviços de acolhimento e a adoção. Nessa investigação, nos apoiamos em referenciais teórico-metodológicos relacionados aos estudos foucaultianos e ao campo do jornalismo televisivo com o intuito de analisar alguns programas e séries jornalísticas exibidas pela Rede Globo de Televisão, entre 2008 e 2010, que visibilizaram tanto os serviços de acolhimento como a adoção. A escolha da emissora se fez em função da sua grande abrangência junto à população brasileira, que seria de $98,47 \%{ }^{2}$, pois buscávamos conhecer o que vinha sendo dito e largamente difundido sobre a questão, chegando a muitos 
brasileiros e, assim, impactando seus modos de ver, ser e posicionarse.

No âmbito desse estudo, entre outros aspectos, constatamos que o direito à convivência familiar e comunitária ${ }^{3}$ era abordado através de certos enfoques, que entendemos ser estratégicos, pois recortavam tal questão, por exemplo, ao lançar um foco especial sobre a situação de crianças ${ }^{4}$ que se encontravam em abrigos ${ }^{5}$ ou ao veicular histórias, em regra bem-sucedidas, de pessoas que adotavam. Nesse sentido, a mídia contribuía para produzir um determinado olhar sobre esses sujeitos, nos convidando a assim também ver, nos comovendo e incitando a uma vontade de família - um enunciado, na acepção que Foucault (2004a) atribui a esta expressão, que atravessava os materiais que analisamos.

Neste artigo trazemos algumas das análises realizadas de modo a dar visibilidade e problematizar tal incitamento, colocando em questão as formas como a mídia acaba estabelecendo verdades sobre esta política pública, atribuindo-lhe certos contornos. Não nos ateremos à discussão nem do referido direito nem ao tema da adoção, remetendo - leitor a trabalhos que nos serviram de referência (Rizzini, Rizzini, Naiff, \& Baptista, 2007; Silva \& Arpini, 2013). Dos materiais analisados na pesquisa, aqui lançaremos mão de cenas do telejornal Jornal Hoje, na série de reportagens nomeada Filhos do Coração FC1 ${ }^{6}$ (Rede Globo de Televisão, 2008) e Filhos do Coração - FC2 (Rede Globo de Televisão, 2009-2010) e do programa Globo Repórter - GR ${ }^{7}$ (Rede Globo de Televisão, 2010).

Cabem alguns apontamentos sobre a escolha de produções midiáticas como objeto de análise. Discussões teóricas e pesquisas tem afirmado a efetividade da mídia na constituição dos sujeitos. A mídia "não apenas veicula, mas constrói discursos e produz significados, identidades e sujeitos" (Fischer, 2002, p. 588). Entendemos que esse território constitui um importante modo de visibilidade em relação ao que é possível ser dito em uma determinada época, portanto, do que é possível ser considerado como verdade, que, para Foucault (2006), não está apenas ligada ao domínio da ciência, mas também aos sistemas de informação.

A escolha em trabalhar com produções jornalísticas foi atravessada pelo fato de que, tradicionalmente, lhes é atribuída grande credibilidade, o que inscreve este território midiático em um regime de verdade, de visibilidade de verdades ditas reais. Dessa forma, o jornalismo mostra-se como uma mídia distinta, no que tange à busca e à veiculação daquilo que "realmente" poderia ser considerado como uma verdade. Tal conformação do território jornalístico produz efeitos subjetivos importantes, na medida em que asseguraria aquilo que os sujeitos poderiam qualificar como verdadeiro. Além disso, 0 jornalismo ${ }^{8}$ faz uso de recursos dramáticos, como a novelização, termo que alguns autores da Comunicação têm utilizado para discutir 
a apropriação jornalística do roteiro ficcional ${ }^{9}$ (Alencar, 2010) e, atualmente, também se caracteriza pelo que tem sido chamado de infotainment - termo que traduz o embaralhamento das fronteiras entre a informação e o entretenimento (Gomes, 2010).

Estas diferentes estratégias utilizadas pela mídia jornalística em geral nos capturam pela sedução à vontade de verdade, pela construção de narrativas e imagens que, a exemplo do jornalismo investigativo, buscam a verdade lá onde ela realmente estaria: na rua, na casa, no corpo, na dor, na alegria de cada sujeito. Mostram, dessa maneira, histórias que não são de qualquer vida, mas sim de uma vida dita real - embora tais narrativas, assim como as ficcionais, são produzidas e nos convocam a ver determinadas coisas (não outras, também possíveis). Ao estarem relacionadas aos fatos cotidianos, acabam ofertando - e rechaçando - determinadas posições de sujeito e modos de viver como mais ou menos aceitáveis. E, neste jogo, contribuem para a naturalização de certos modos de olhar e compreender o mundo.

Para tecer a análise dos materiais, seguimos a concepção de discurso de Foucault (2004a), entendendo-o como uma prática que forja objetos. O filósofo nos convida a problematizar os discursos para que, assim, possamos discernir como as coisas estão dispostas, como foram montadas. Tal convite propõe que interroguemos suas condições de existência enquanto verdades para pensarmos sobre outras possibilidades de habitar o mundo, quem saber produzir outras verdades que abram brechas à composição de relações a partir do diálogo com diferentes posições de sujeito. Relações que possam tomar distância dos grandes blocos discursivos que tendem a capturar a vida em formas de subjetivação totalizantes, que tentam instituir apenas alguns modos de existência como legítimos. Trilhar este caminho não significa que procuramos algo oculto atrás dos discursos - não há nada por trás das cortinas, toda a realidade está manifesta -; visamos sim visibilizar os ditos e não ditos, o que está sendo enunciado nos discursos. Sustentadas nas concepções de Foucault (2004a), operamos com a descrição das coisas ditas, uma análise que não está interessada em interpretações que cristalizam, mas na compreensão do modo como as coisas são passíveis de existência.

Ao mapear alguns ditos visibilizados pelo jornalismo televisivo sobre as estratégias à efetivação do direito à convivência familiar e comunitária, buscamos, na sequência, estranhar os modos de olhar/pensar crianças e adolescentes que necessitam dos serviços de acolhimento e da prática da adoção para garantia do referido direito, e colocar em questão o incitamento a uma vontade de família. A discussão acerca de alguns dos (possíveis) efeitos subjetivos destes discursos na constituição dos sujeitos é tramada de forma interrelacionada. 


\section{Da urgência do tempo}

Nos materiais analisados, nos chamou atenção, primeiramente, a ênfase dada ao tempo de espera das crianças em um serviço de acolhimento; através de imagens e metáforas, como a do relógio sem sincronia (o da criança gira rapidamente, sem parar; no das famílias - que demorariam em reunir as condições requeridas para tê-las -, os ponteiros se movem muito devagar), aponta-se uma pressão temporal. Essa sustenta discursos que demarcam que tais crianças estão perdendo suas infâncias longe de uma família. Assim, coloca-se em jogo regimes de verdade que constituem um modo de olhar quem se encontra em um serviço de acolhimento: esse seria um sujeito que não teria mais do que perdas e abandono em sua vida. Diz-se que as crianças, ao se encontrarem fora de um círculo familiar, tornar-seiam crianças sem infância. Formas de tecer um enunciado que afirma: sem família, logo, sem infância.

Um modo de olhar, mas reafirmado como uma verdade, pois o jornalismo, como assinalamos acima, traz consigo a ideia da produção de um retrato da realidade (Gomes, 2009). No entanto, para inquietar e desacomodar uma tradição que cola imagem e verdade, lançamos mão da provocação de Fischer (2011, p.1) ao interrogar: "quando falamos em histórias (ou em narrativas), estamos falando necessariamente de histórias reais de vida?".

A questão da temporalidade e da urgência é tão central que a encontramos anunciada já na segunda reportagem da série FC1, que propõe mostrar "quem são os meninos e meninas que perdem a infância nos abrigos a espera de adoção?". Aqui é interessante atentar, também, para um dos recursos imagéticos utilizados, pelo qual vemos os contornos de um relógio servirem de moldura para a veiculação de cenas de crianças em movimento, sob ângulos que não permitem sua identificação, ao som de uma singela música instrumental. Ao mesmo tempo, ouvimos em off a voz do coordenador de uma Vara da Infância e Adolescência explicar que o direito da criança e do adolescente é o de ser criado no seio de uma família, pois se "você demora na solução da problemática da criança e do adolescente, você vai perder essa infância, essa juventude e, ao invés de transformar esse jovem em cidadão, possivelmente vai tirar dele esse direito de cidadania" (FC1).

Na sequência, outra fala de um especialista, agora um promotor, enfatiza a mesma urgência em reinserir a criança em uma família, sob pena de que ela pereça em serviços de acolhimento que, longe de serem caracterizados como uma medida de proteção (provisória e excepcional, pois acionada frente à ameaça ou violação de direitos) 10, são qualificados como "depósitos de gente". Em suas palavras, 
não devemos "traumatizar as crianças nem deixar que elas pereçam em depósitos de gente por falta de amor e em nome de uma pobreza romântica, demagógica que precisa ser vencida" (FC1).

A convocação de especialistas, portadores de um saber sobre a infância que necessita de uma medida protetiva, quer reforçar a veracidade característica das produções jornalísticas. Ela funcionará como um sistema de perícia (Miguel, 1999) que, ao demarcar o que é "a" verdade, permitirá estabelecer a confiança dos sujeitos atravessados cotidianamente pelas notícias e reportagens jornalísticas. Veracidade e perícia que contribuem para a constituição subjetiva na medida em que certificam aquilo que os sujeitos (interpelados por estas produções) passam a considerar como verdadeiro.

Frente a arranjos discursivos como os apontados acima, interrogamos a serviço de que esta noção de uma infância perdida precisaria ser constantemente reiterada? Que possibilidades e posições subjetivas são produzidas, quando passamos a olhar tais crianças apenas pelo viés da perda e do abandono? Na ótica de uma psicóloga, na reportagem que abre a série $\mathrm{FC} 1$, uma criança de abrigo é "uma criança que não pertence a ninguém, então são crianças que permanecem no limbo, são crianças que crescem com uma identidade de órfãos ou abandonados sem se reconhecerem como pessoas que pertencem a alguém ou a algum lugar".

Palavras fortes que marcam e produzem certos corpos infantis nos fazendo perguntar: por que um abrigo não pode ser visibilizado como um lugar onde uma criança pode se sentir protegida e, mais ainda, pertencente à comunidade que ali se constitui enquanto (provisoriamente) nele viver? Para além da espera, não haveria possibilidades de laços de convivência pautados pelo cuidado e afetividade? Ou, no espaço do abrigo, a vida estaria sempre fadada à interrupção, à espera de um destino que conduza as crianças, enfim, a "viver a infância num local abençoado, onde só faltavam elas" (repórter, GR) - ou seja, no seio de uma família que viria a adotá-la? Também nos chamou atenção o quanto na série Filhos do Coração a produção das imagens, quando mostram crianças em serviços de acolhimento, como os abrigos, apresentam um caráter sombrio; numa das reportagens um bebê aparece sozinho, sentado no berço, fazendo movimentos de embalo ao segurar as grades de proteção do mesmo - cena que, como tantas outras, tem pouca luminosidade e muitas sombras. Composições imagéticas que caracterizam um modo específico, entre outros, de mostrar, ou produzir, uma "realidade".

Consideramos importante ressaltar que aquilo que ganha visibilidade é político e gera efeitos nos sujeitos que assistem. Ponto interessante para trazer um comentário de Wenders (2005), a respeito da produção cinematográfica, que pensamos ser igualmente pertinente quando se refere aos materiais da mídia jornalística, ressaltamos que 
as imagens registradas na película podem ser geradoras de danos. Por esse motivo, o cineasta não busca captar imagens relacionadas à violência ou ao sexo quando produz seus filmes, pois "lo que se muestra a diário a la gente, a la gente, a las personas, es político" ( $p$. 68). Se o que é visibilizado diariamente não está isento de um posicionamento político, não se trata de entender se as imagens que nos referimos ao longo deste trabalho são boas ou ruins, se tem boa qualidade ou não, mas sim de pensarmos sobre o que elas dizem em relação aos modos como objetivamos (e subjetivamos) o ser-criança que necessita de um serviço de acolhimento ou passa por um processo de adoção.

Cabe, portanto, insistir sobre o peso da veracidade que as imagens assumem em nossa cultura, pois aquilo que é posto à mostra pela exibição de uma fotografia ou filmagem nos dá a impressão de ser uma cópia fiel do "real", daquilo que realmente aconteceu (como se a captura de imagens pudesse pegar a "própria coisa", tal como ela verdadeiramente seria). No entanto, será que podemos falar da existência de "coisas em si"? Acreditamos ser mais interessante trabalhar com a noção de produção de cenas e narrativas que, ganhando visibilidade na mídia, nos oferecem certas perspectivas, em detrimento de outras. Estas nos convocam a olhar (ao mesmo tempo em que também somos, por elas, olhados) para aquilo que, além de estar delimitado pelos ângulos de uma câmera, só entrou em cena depois de passar por uma edição - que também constrói um modo de olhar para o que entra em cena.

Outra tônica que perpassa as reportagens analisadas é a idéia de que uma criança em abrigo é, consequentemente, uma criança infeliz. Há, na série FC2, um pequeno diálogo no qual a repórter pergunta a duas crianças: "Que que precisa para ser feliz?" Ao que uma delas responde: "Ser adotado". Aparentemente, um simples diálogo. No entanto, ele expressa como, ao nos depararmos com uma criança em um abrigo, somos interpelados por um pressuposto que parece naturalizado em nossa sociedade: que criança não é feliz, ou ainda, que nenhuma criança, ao estar (temporariamente) em um serviço de acolhimento, pode estar feliz. O que soa quase como um imperativo, um outro enunciado que compõe os regimes de verdade que objetivam essas crianças ao nosso olhar. Deste modo, a felicidade, assim como a vivência da infância, só seria possível à criança que se encontra em família. É o que também vemos na animação do logo da série Filhos do Coração, no qual um boneco, que representa uma criança (no primeiro momento sozinho em cena), aparece com uma expressão fechada, sem sorriso. Na medida em que outros elementos do logo vão surgindo, como a grama, a palavra coração, a casa, o sol ao fundo, e que os bonecos-adultos se aproximam (representando um pai e uma mãe), um sorriso se esboça no rosto do bonecocriança. 
"Verdade" que também é sustentada por especialistas convocados a falar sobre a importância da permanência da criança em família e dos riscos em estar fora dela. A primeira reportagem da série FC1 traz cenas que tratam desta convocação. Ao acompanhar imagens como a de um bebê, sentado no berço segurando suas grades, de uma criança deitada na cama, com as pernas encolhidas, de outra, comendo uma refeição de costas para a câmera e, por último, de uma menina que, ao andar de motoca, a empurra com os pés (ao invés de pedalá-la), somos informados que "segundo psicólogos, crianças que crescem em abrigos, sem atenção exclusiva, têm carência afetiva, baixa autoestima, atraso no desenvolvimento físico e psicológico e saúde frágil" (FC1).

Aspectos negativos que se tornam ainda mais pesados quando afirmados de modo tão categórico. Seriam tais características exclusividade e condição de toda e qualquer criança que cresce em um abrigo? Que saberes são esses, de uma psicologia que fabrica e faz etiqueta para os sujeitos a partir de algo que, muitas vezes, ao invés de impulsionar a potência e afirmação de suas vidas, parece apenas diminuí-la? Se pelos discursos científicos objetivamos a infância para melhor compreendê-la, se faz prudente não amarrá-la a territórios sombrios e "menores".

Através das reportagens, somos convidados a ver mais os riscos e as perdas quando se trata de um serviço de acolhimento que, paradoxalmente, foi criado para a proteção de crianças e adolescentes que tiveram seus direitos ameaçados ou violados. Que haja riscos, perdas e dor neste processo, não se pode negar (nem é o objetivo deste texto). Mas que seja esse um dos principais pontos a ganhar maior visibilidade em uma série especial, de um tradicional telejornal diário (da maior rede nacional de telecomunicações), nos provoca a pensar como queremos olhar e sermos olhados pelas crianças e adolescentes que necessitam passar parte de suas vidas em um serviço de acolhimento.

\section{Sobre a produção de um comoVer à adoção}

Um dos efeitos que os discursos e as imagens que compõem as reportagens analisadas produzem em nós diz respeito a um determinado modo de olhar as crianças e adolescentes abrigados; elas nos convidam a ver crianças sem infância e infelizes que "esperam anos em instituições pelo aconchego do colo de um pai e de uma mãe" (repórter, FC1), que estão, portanto, "apartadas da sociedade" (juíza, FC2). Mas há, também, outro aspecto que perpassa tais reportagens: os efeitos produzidos pelas estratégias que buscam nos capturar pela via da emoção, por uma comoção em relação aos depoimentos e histórias de vida visibilizadas. Juntos, esse 
modo de ver (crianças, adolescentes e suas famílias) e essa comoção em relação a suas histórias, caracterizam o que passamos a chamar de um comover à adoção - que engendra e incita, nada incidentalmente, a uma vontade de família.

Assim, compreendemos essas produções como um convite a adotar, pois as reportagens que nos remetem à falta que há na vida de crianças e adolescentes que passam pelos serviços de acolhimento nos afetam e sensibilizam a realizar um ato reiteradamente caracterizado como de amor: a adoção. Neste sentido, dúvidas e receios sobre o tema são trabalhados em reportagens que, por vezes, de modo didático, trazem o objetivo e ações desenvolvidas por documentos e políticas que regulam a prática da adoção. Ao mesmo tempo, convocam a falar de si aqueles que já adotaram uma criança, mostrando aos telespectadores que esta é uma escolha possível e pautada pelo coração. Um convite que se compõe de um forte apelo emocional, incrustado em reportagens que conduzem cenas de afeto entre pais e filhos emocionados ao falar de suas próprias histórias. Lembrando que produzir e visibilizar lições de vida com intensa carga emocional é uma estratégia de captura recorrente nos meios de comunicação, porque bastante eficaz (Sodré, 2006).

Assim, acompanhamos cenas em que o amor aparece como o elo fundamental que sustenta a relação entre estes pais e filhos. Distinta das relações entre a família de origem, ela não é amarrada por laços sanguíneos: "os laços que unem essas famílias não são de sangue, são de amor" (repórter, FC2).

Em meio a depoimentos de quem adotou, cenas de afeto em família, onde pais e filhos brincam e trocam gestos de carinho são veiculadas, frequentemente, acompanhadas, ao final, de uma música instrumental suave ao fundo. Cenas que nos tocam emocionalmente, assim como a fala da apresentadora, que, em dado momento, comenta: "adotar é doar, um ato de entrega absoluta, de amor incondicional" (GR). É interessante observar que quem apresentou esta edição do Globo Repórter não foi Sérgio Chapelin (que há anos está à frente do mesmo), mas a apresentadora Glória Maria, que adotou duas meninas em 2009. Diferente dos pais que disponibilizam seus depoimentos ao programa, ela não conta sua história, mas essa fica implícita, visto que sua escolha em adotar difundiu-se entre a população brasileira, pois foi bastante veiculada pela própria mídia.

Embora histórias de pais adotantes apareçam em diversos momentos da série Filhos do Coração, essa temática se concentra e ganha exclusividade nas últimas reportagens de ambas: na FC1 se intitula "Histórias de adoção", na FC2 é denominada "Histórias de homens e mulheres que decidiram formar uma família". Há, nessas séries, uma seqüência que caracteriza um enredo crescente nas reportagens (veiculadas em dias seguidos) que mostram, primeiro, crianças que se encontram em abrigos e terminam com as histórias e depoimentos 
sobre a adoção. Na última reportagem da série $\mathrm{FC1}$, a adoção é apresentada como um gesto pelo qual "muitas famílias descobriram um amor tão forte que só quem sente pode explicar". Desse modo, nos convida a assistir "exemplos dessa felicidade" (repórter, FC1) que nos falam de "uma alegria que só quem ta sentindo mesmo tá sabendo" (mãe, FC1), pois "a satisfação dos pais, a alegria das crianças, só quem já experimentou sabe, não há nada como bons momentos em família" (repórter, FC2).

Cabe mencionar que a relação que se estabelece entre imagem e telespectador nunca é unilateral, pois sempre existirá um apelo à nossa própria participação: "trata-se de estratégias e de um repertório de idéias que vão sendo estabelecidos e tecidos também por nós, espectadores e, que contribuem para a construção do verídico" (Marcello, 2010, p.136). Como propõe Lopes e Veiga-Neto (2004), o interesse do telespectador não reside em uma (suposta) vontade própria ou autonomia do olhar, mas "se funda nos muitos regimes de verdade que nos interpelam e que acabam constituindo cada um de nós" (p. 232).

É pertinente retomar aqui um aspecto que foi citado na introdução deste artigo. $O$ frequente uso de recursos dramáticos no telejornalismo nacional caracteriza um fazer jornalístico novelizado e, também, remete ao que tem sido chamado de infotainment ${ }^{11}$ (Gomes, 2010). Aspecto que pode ser discernido em expressões, que muitos de nós empregamos no dia-a-dia, como "isso parece coisa de filme" ou "que novela", para as narrativas que acompanhamos no território jornalístico. Neste embaralhar de fronteiras, as estratégias jornalísticas que apelam ao emocionar-se, à novelização, longe de dissolver a confiança e a veracidade (marcas de tal campo) as potencializam.

No decurso das reportagens, adotantes e adotados são convidados a falarem de si, de seus sentimentos, dificuldades e emoções; são convocados a trazer seu próprio testemunho, para que, então, nós telespectadores possamos compreender como é ser um pai e uma mãe que adota uma criança - e, assim, talvez, desmistificar estereótipos e receios que acompanham o processo. E, quem sabe, deste modo, pela emoção de cada uma das "histórias de homens e mulheres que decidiram formar uma família" (título da reportagem, FC2), não seremos também instigados a uma vontade de adotar que, em última análise, diz respeito a uma vontade de família, expressada no trecho a seguir:

a gente não adota uma criança para fazer o bem, sabe, e é muito interessante isso, porque é muito comum você falar: ah, puxa vida, chegou o nosso filho, e as pessoas falam, puxa, parabéns, você tá fazendo algo tão belo, algo bonito. Você não adotou ninguém pra ser bonzinho, pra resolver um problema 
social, né; você adotou porque você quer constituir uma família. Porque fundamentalmente é isso que as pessoas não entendem. Você tem necessidade de ter uma criança, de ouvir o riso de uma criança que você tá fazendo feliz e que te faz feliz, entendeu? (pai, FC2)

Nas histórias sobre adoção visibilizadas, se evidencia a tentativa de mostrar que não há diferença entre filhos adotivos e biológicos, pois "o amor que se sente pelo filho biológico ou adotado é exatamente o mesmo, e esse amor nasce com a convivência" (pai, FC1). No entanto, muitas vezes, tal diferença é marcada pelo simples uso da nomenclatura adotado (demarcador quase "natural" ao falar sobre), junto à palavra filho. Como na reportagem em que ouvimos falas que afirmam: "e amanhã você vai se emocionar mais com os depoimentos de pais que abriram o coração para os filhos adotivos" (repórter, FC2).

Nas reportagens nos é oferecido, também, um modo de ser família adotante (ou substituta, nos termos da política) que parece ter a necessidade de ser melhor ou mais potente do que uma família de origem. O que se torna visível em discursos que, apoiando-se em saberes especialistas, clamam pela desmistificação da adoção; essa não deve ser escondida, ao contrário, as positividades dos pais e filhos adotantes devem ser enfatizadas. Ditos que se atualizam na veiculação de uma pesquisa que, segundo a série $F C 1$, surpreendeu os psicólogos: filhos adotivos mostram os pais como mais participativos e mais envolvidos.

Nos materiais que focam a adoção, divisamos dois incitamentos em jogo: um que faz falar sobre si quem se envolve no processo (da expectativa da espera, da emoção de ter um filho, das dificuldades enfrentadas, do amor que tudo supera) e outro que nos instiga a adotar uma criança. Ambos estão interligados, pois o incitamento a falar sobre si, ao nos emocionar, opera como tática que tem como objetivo nos comover à possibilidade da adoção. Através dessa, por um lado, oferecemos um lar às crianças que aguardam (por uma família) nos serviços de acolhimento, possibilitando-lhes (na perspectiva das reportagens analisadas) um retorno à infância, que estaria interrompida. Ao mesmo tempo, seria suprida - ou produzida - certa vontade de família que - então - habitaria cada adulto-casal. Foucault (2011) pontua que o incitamento a dizer a verdade sobre si, de confessar sentimentos, atitudes e desejos está intimamente ligado aos procedimentos que surgiram, ao longo dos séculos, para a produção de uma verdade sobre o sexo. Segundo o autor, a era vitoriana marcou "uma verdadeira explosão discursiva" (p. 23) em torno do tema, abrindo a possibilidade para outros campos de saber, como a medicina e justiça penal, se ocuparem da questão, e ajudar a intervir na gestão das populações. Engendra-se, neste contexto, uma 
nova técnica de poder que opera o controle social, a condução de condutas (no caso, da sexualidade) através da criação de uma série de "dispositivos para falar, ouvir, registrar, procedimentos para observar, interrogar, formular" (Foucault, 2011, p. 34).

Investigando a produção de uma verdade de si no âmbito da sexualidade, Foucault (2011) chamou a atenção para a prática da confissão, que acabou extrapolando para outros tantos tipos de relações. Assim, podemos compreender como, na modernidade, 0 incitamento à confissão de si passou a ser uma prática importante à constituição subjetiva, forjando modos de ser e posições de sujeitos. No que concerne a este estudo, não só uma verdade sobre os sujeitos, mas uma verdade sobre o que é ser e como se faz para ser uma família "de verdade". E, nesse sentido, um bom pai e uma boa mãe.

Através destas tessituras, que nos falam sobre a disseminação da prática de colocar em discurso a verdade sobre si, pensamos ser potente problematizar os depoimentos e as histórias de vida que ganham grande espaço nos materiais analisados. Ao que tal convite, que faz falar sobre um processo de adoção e sobre o desejo de ter uma família, estaria relacionado se não à exposição, à revelação da verdade de cada um? Verdade que, por sua vez, se coloca como possibilidade subjetiva a outros sujeitos.

Uma concepção interessante para pensar a questão da verdade de si articulada ao território midiático é o que Fischer (2002) denomina dispositivo pedagógico da mídia, um aparato discursivo e não discursivo através do qual se dá um incitamento constante à revelação de si mesmo. Tal dispositivo engendra a "produção e veiculação de saberes sobre os próprios sujeitos e seus modos confessados e aprendidos de ser e estar na cultura em que vivem" (Fischer, 2002, p. 155), pois, para a autora, a mídia opera no aprendizado dos modos de existência. Nesse sentido, uma tarefa importante é tentar compreender as formas como a mídia opera, as estratégias que lança mão para que aconteça este aprendizado, o que ensaiamos fazer aqui. Importante pontuar que, a partir de nossa perspectiva teórico-política, a relação que se processa entre os sujeitos e o que é oferecido pela mídia não é uma relação de causa e efeito, tampouco de manipulação ideológica. Entendemos, junto com Fischer (2002, p.153), que a mídia participa "efetivamente da constituição de sujeitos e subjetividades, na medida em que produz imagens, significados, enfim, saberes que de alguma forma se dirigem à "educação" das pessoas, ensinando-lhes modos de ser e estar na cultura em que vivem". Contudo, trata-se de um processo logo, aberto a plurais atravessamentos, a despeito de algumas linhas de força serem muito potentes e operarem enraizamentos.

A veiculação da revelação de si, que nos oferece e ensina modos de como ver à adoção, é uma constante na série Filhos do Coração e no 
Globo Repórter. Ela acontece através de depoimentos que nos falam de salvação: "esse aqui é um anjo na minha vida... ela veio pra salvar meu casamento, ela veio pra salvar minha família... eu só tenho que agradecer a Isabel" (mãe, GR), de mudança: "depois que conheci o Davi, realmente... o valor das coisas ficaram diferentes né, o valor da vida mesmo" (mãe, GR), e de orgulho: "nós somos uma família adotiva... e nos orgulhamos profundamente de ter experimentado essa via de amor e tamos adorando essa experiência, tem sido um caminho mágico" (pai, FC2).

Então, frente ao aval de saberes psi, entre outros, e da verdade de si de cada depoimento, como não nos convencermos de que "esse é o verdadeiro amor, você amar a diferença, amar a mãe quando tá irritada, o pai quando faz alguma coisa pra você que não te agrada, esse é o verdadeiro amor, né, é o amor que sustenta tudo" (mãe, FC1)?

A partir das reportagens analisadas, nas quais o que está em jogo é uso de estratégias discursivas que sustentam este modo de comover à adoção, é possível tecer considerações sobre a dimensão do sensível que, na relação comunicativa, enlaça as visibilidades midiáticas e os sujeitos interpelados por elas. Conforme nos fala Sodré (2006), atualmente há uma espécie de espírito do tempo que se encontra marcado não apenas pelo racional, mas pela imagem e pelo sensível. Uma dimensão que se faz "reconhecer como relação entre duas subjetividades, entre os interlocutores" (p.10). Questão que, segundo o autor, pode ser sintetizada na interrogação: quem seria o outro com quem me comunico?

A proposição de um pensar sobre os aspectos da relação comunicativa que não se detêm em lógicas argumentativas e da racionalidade linguística abre espaço para o que o autor chamou de estratégias sensíveis. Essas se caracterizam pelos "jogos de vinculação dos atos discursivos às relações de localização e afetação dos sujeitos no interior da linguagem" (Sodré, 2006 p. 10), que salvaguardam aos indivíduos o lugar singular do afeto. Experiências sensíveis que tornam nebulosa a capacidade autorreflexiva dos sujeitos, pois, junto à multiplicidade de sentimentos e emoções que se compõem nessa dimensão, haverá sempre a transmissão de algo que perpassará os sujeitos sem que lhes seja possível saber direito do que se trata. O que coloca uma questão importante para pensarmos: qual seria o encaminhamento político dado às nossas emoções, visto que signos (vivíveis e sonoros) também administram o afeto coletivo (Sodré, 2006)?

Deste modo, não apenas as leis e as políticas públicas compõem as estratégias que forjam a gestão - a condução das condutas ou o governo - da população de crianças e adolescentes que se encontram nos serviços de acolhimentos e daqueles que, de uma forma ou outra, se vinculam a ela. Também o apelo emocional e a comoção 
que se constitui na relação que estabelecemos com o que é visibilizado pela mídia acabam fazendo parte destas estratégias de gestão. Se o comoVer nos coloca para "além da era em que prevalecia o pensamento conceitual, dedutivo e sequencial" (Sodré, 2006, p. 12), como duvidar da força da captura pelo afeto?

Diante destas estratégias - que colocam a possibilidade de viver a infância e ter felicidade somente para a criança que está inserida em uma família, e que nos comovem à adoção -, produzidas ou, no mínimo, atualizadas constantemente pela mídia, consideramos ser pertinente um diálogo com as questões relacionadas ao que Foucault (2004b) chamou de governamentalidade. Tal conceito ferramenta nos auxilia a pensar o governo de si e dos outros na gestão da vida em sociedade e remete ao

conjunto constituído pelas instituições, os procedimentos, as análises e reflexões, os cálculos e as táticas que permitem exercer essa forma bem específica, embora muito complexa, de poder que tem por alvo principal a população, por principal forma de saber a economia política e por instrumento técnico essencial os dispositivos de segurança. (p. 143)

Esta governamentalidade, que constitui uma arte de governar, busca uma maneira correta de dispor as coisas para melhor conduzi-las, não necessariamente ao bem comum, mas a um objetivo adequado a cada uma das coisas a governar (Foucault, 2004b), a partir de um exercício de poder que assume uma forma econômica (Foucault, 2009). Trata-se de uma nova arte de governar, que foi se produzindo e transmutando a partir do século XVI, correlativa ao surgimento da população como um campo de intervenção, da economia como um domínio específico de realidade e da economia política como técnica de intervenção do governo. Assim, estabeleceu-se uma tríade formada por governo, população e economia política, que permanece articulada até os dias de hoje. Com essa nova forma de exercício do poder, buscar-se-á um fim adequado para cada coisa a ser governada.

Neste processo, a família, no interior da população, passará a ser instrumento de intervenção ao governo, assumindo uma função política e tornando-se um segmento privilegiado, "porque, quando se quiser obter alguma coisa da população quanto ao comportamento sexual, quanto à demografia, ao número de filhos, quanto ao consumo, é pela família que se terá efetivamente de passar" (Foucault, 2009, p. 139). A meta do governo será a melhora da sorte das populações, seja agindo sobre essa direta ou indiretamente. Diante dessa articulação política, é inevitável questionar: se o governo das populações passa por uma intervenção na família, na 
busca por atingir determinadas finalidades, como conceber que alguns estejam fora dela?

\section{$4 \mathrm{Um}$ fecho que abre: interrogando nossos modos de pensar}

Se é sobre a família que devem incidir as táticas que possibilitam uma arte de governar que conduz a conduta das populações, nada mais estratégico do que buscar integrar à família aqueles que, como as crianças que passam por um serviços de acolhimento, estão fora dela. Portanto, ao mesmo tempo em que vemos a construção leis e planos (estratégias, enfim) no campo das políticas públicas que visam assegurar direitos sociais - o direito à convivência familiar e comunitária de crianças e adolescentes -, entendemos e apontamos que essas não guardam exterioridade com estratégias outras, no caso, operadas ou atualizadas a partir da mídia midiáticas, como o incitamento a uma vontade de família que busca mobilizar os sujeitos à adoção.

Em uma busca que "corre contra o tempo", de forma que crianças e adolescentes tenham o seu direito assegurado, é importante que possamos atentar aos modos de pensar que se produzem neste processo. Buscamos mostrar, no tensionamento de alguns discursos e imagens veiculadas nos programas analisados, que são colocadas a certas crianças e adolescentes posições subjetivas marcadas por uma suspensão da vida, da felicidade, que só poderia ser garantida em um futuro indeterminado, mas circunscrito, pois ligado à (re)inserção familiar.

Em tal ordenamento discursivo, somos seduzidos a um modo de objetivar e, portanto, de compreender essas crianças e adolescentes como sujeitos que perdem algo - sua infância - à espera de uma família. Não haveria um modo alternativo para compreendê-los, pois tudo se apresenta como se essas fossem as suas únicas possibilidades subjetivas. Em razão disso, submerge algo fundamental, que é a razão da existência dos serviços de acolhimento. Crianças e adolescentes encontram-se nesses espaços porque necessitam dele como uma medida de proteção - e há que se trabalhar para que haja proteção e acolhimento no sentido pleno que estas medidas implicam.

Há uma série de fatores sociais e econômicos que levam tais sujeitos a viverem parte de suas vidas nesses serviços, mas que ficam relegados à invisibilidade, como "não existentes". Além disso, quando se mostram os motivos que levaram uma criança a viver, temporariamente, em um abrigo, frequentemente (só) se focam questões que acabam contribuindo para culpabilizar seus cuidadores 12. Dificilmente se atenta para as implicações que nossa organização social tem na produção, por exemplo, de mães como usuárias de 
drogas e/ou prostitutas (características apontadas na série Filhos do Coração ao trazer o histórico de algumas crianças que passaram por um serviço de acolhimento).

Com a ênfase na urgência de efetivar o convívio familiar, forjamos não apenas determinadas posições de sujeito para os meninos e meninas que passam parte de suas vidas em serviços de acolhimento, como também se engendra um modo específico de olhar para esta população que invisibiliza outras possibilidades, aquelas sustentadas pelo reconhecimento da potência de vida desses sujeitos e não pela sua negação. Entendemos que cuidado e afeto são possíveis fora do circulo familiar, no laço comunitário que os serviços de acolhimento constitui para muitas crianças e adolescentes - ainda que o comunitário seja uma questão praticamente esquecida quando se trata de falar em direito à convivência familiar e comunitária.

Longe de tentar conjecturar sobre o que é $O$ melhor ou $O$ pior, assumindo uma perspectiva maniqueísta em relação ao tema, ou fazer apologia aos serviços de acolhimento, a questão fundamental deste trabalho foi tensionar e dar visibilidade aos discursos e às relações que estabelecemos com quem vive - transitória ou (não tão raramente) grande parte dos anos da infância ou adolescência) - em tais espaços. Discursos que se articulam nas estratégias de governamento que operam nas políticas sociais e que, no embate de forças para que algo ganhe visibilidade no campo midiático (enquanto outras permanecem na invisibilidade), produzem efeitos subjetivos, forjando determinados modos de pensar, viver a infância, adotar, entender-se, relacionar-se, desejar. Mas plurais formas podem existir.

\section{Referências}

Alencar, H. C. de. (2010 setembro). Quando a suíte vira novela: uso de estratégias narrativas ficcionais no telejornalismo. Anais do XXXIII Congresso Brasileiro de Ciências da Comunicação. Caxias do Sul, RS, Brasil. Recuperado em 10 de dezembro, 2011, http://www.intercom.org.br/papers/nacionais/2010/resumos/R 5-1889-1.pdf

Brasil. Lei 8.069 de 13 de julho de 1990 (1990). Estatuto da Criança e do Adolescente. Diário Oficial da República Federativa do Brasil. Brasília/DF.

Brasil. (2006). Plano Nacional de Promoção, Proteção e Defesa do Direito de Crianças e Adolescentes à Convivência Familiar e Comunitária. Brasília/DF.

Brasil. Lei 12.010 de 3 de agosto de 2009 (2009). Dispõe sobre adoção. Brasília/DF. Recuperado em 05 de novembro, 2011 de 
http://www.planalto.gov.br/ccivil_03/_Ato20072010/2009/Lei/L12010.htm

Fischer, R. M. B. (2002). O dispositivo pedagógico da mídia: modos de educar na (e pela) TV. Educação e Pesquisa, 28(1), 151162.

Fischer, R. M. B. (2011). Imagens e ficções: anotações para Seminário 2011-1. Porto Alegre: PPGEDU/UFRGS.

Foucault, M. (2000). A ordem do discurso. São Paulo: Edições Loyola. Foucault, M. (2004a). A arqueologia do saber (7a ed.). Rio de Janeiro: Forense Universitária.

Foucault, M. (2004b). A Governamentalidade. In: R. Machado (Org.). Microfísica do Poder. (2a ed., pp. 277-293). Rio de Janeiro: Graal.

Foucault, M. (2006). Poder e saber. Ditos e escritos 4 (2a ed., pp. 223-240). Rio de Janeiro: Forence Universitária.

Foucault, M. (2009). Segurança, Território e População. São Paulo: Martins Fontes.

Foucault, M. (2011). História da Sexualidade 1: A vontade de saber. Rio de Janeiro: Graal.

Gomes, I. M. M. (2010). O Infotainment e a cultura televisiva. In J. F. Filho (Org.). A TV em transição: tendências de programação no Brasil e no mundo. (pp.195-212). Porto Alegre: Sulina.

Gomes, W. (2009). Jornalismo, fato e interesse: o fato como problema. Jornalismo fatos e interesses: ensaios de teorias do jornalismo. (Vol. 1. pp. 9-27). Florianópolis: Insular.

Lopes, M. C., \& Veiga-Neto, A. (2004). Os meninos. Educação \& Realidade, 29(1), 229-239.

Marcello, F. A. (2010). Real versus Ficção: criança, imagem e regimes de credibilidade no cinema-documentário. Educação em Revista, 26(3), 129-150.

Miguel, L. F. (1999). O jornalismo como sistema perito. Tempo Social. Revista Sociologia, 11(1), 197-208.

Rede Globo de Televisão. (2008, fevereiro). Jornal Hoje: Série Filhos do Coração. Rio de Janeiro [Programa de TV].

Rede Globo de Comunicações. (2009/2010, dezembro/janeiro). Jornal Hoje: Nova Série Filhos do Coração. Rio de Janeiro [Programa de TV].

Rede Globo de Comunicações. (2010, setembro). Globo Repórter: Adoção. Rio de Janeiro [Programa de TV].

Rizzini, I., Rizzini, I., Naiff, L., \& Baptista, R. (2007). Acolhendo crianças e adolescentes: experiências de promoção do direito à convivência familiar e comunitária no Brasil. (2a ed.). São Paulo: Cortez.

Silva, M. L., \& Arpini, D. M. (2013) A Nova Lei Nacional de Adoção desafios para a reinserção familiar. Psicologia em Estudo, $18(1), 125-135$. 
Sodré, M. (2006). As estratégias sensíveis: afeto, mídia e política. Petrópolis: Vozes.

Wenders, W. (2005). La verdad de las imágenes. In: W. Wenders (Org.). El acto de ver: Textos y conversaciones. (pp. 59-86). Barcelona: Paidós.

\section{Endereço para correspondência Luciana Rodrigues}

Universidade Federal do Rio Grande do Sul

Instituto de Psicologia

Programa de Pós Graduação em Psicologia Social e Institucional

Rua Ramiro Barcelos, 2600, $3^{\circ}$ andar, CEP 900035-003, Porto Alegre - RS, Brasil

Endereço eletrônico: luciana_rodrig@yahoo.com.br

Inês Hennigen

Universidade Federal do Rio Grande do Sul

Instituto de Psicologia

Programa de Pós Graduação em Psicologia Social e Institucional

Rua Ramiro Barcelos, 2600, $3^{\circ}$ andar, CEP 900035-003, Porto Alegre - RS, Brasil

Endereço eletrônico: ineshennigen@gmail.com

Recebido em: 27/08/2014

Aceito para publicação em: 22/04/2015

\section{Notas}

* Psicóloga, Mestre e doutoranda do PPG em Psicologia Social e Institucional da Universidade Federal do Rio Grande do Sul, Porto Alegre/RS, Brasil.

** Professora do Departamento de Psicologia e do PPG em Psicologia Social e Institucional da Universidade Federal do Rio Grande do Sul, Porto Alegre/RS, Brasil. Doutora em Psicologia pela PUCRS.

1 Trata-se da dissertação de mestrado da primeira autora, sob orientação da segunda autora.

2 Informação extraída do site da própria Rede Globo de Televisão. Recuperado em 19 julho, 2014, de http://comercial2.redeglobo.com.br/atlasdecobertura/Paginas/Totalizador.aspx

3 Raramente a esfera comunitária, que figura na letra da lei, é tematizada na veiculação midiática deste direito.

${ }^{4}$ Apesar da significativa proporção de adolescentes, entre 13 e 15 anos, que se encontram em serviços de acolhimento (conforme o Levantamento Nacional dos Abrigos para Crianças e Adolescentes realizado em 2003), os materiais midiáticos analisados enfocavam quase exclusivamente a situação e a história das crianças. Sem dúvida, um recorte sobre o que acontece no Brasil. Analisar o(s) interesse(s) dessa abordagem, embora assaz pertinente, transcende o escopo daquilo que propomos aqui discutir.

5 Os documentos referentes à garantia do direito à convivência familiar e comunitária definem os locais que acolhem crianças e adolescentes que tiveram seus direitos ameaçados ou violados como Serviços de Acolhimento. Tais serviços podem ser oferecidos nas seguintes modalidades: abrigos institucionais, casaslares, famílias acolhedoras e repúblicas. Neste aspecto também constatamos a ênfase (redutora) na modalidade abrigo.

${ }^{6}$ A primeira exibição dessa série, composta por três reportagens (com duração média de 5 a 6 minutos), foi ao ar durante o mês fevereiro de 2008 . Entre dezembro de 2009 e janeiro de 2010, a série foi retomada com a produção de cinco novas reportagens (com mesma média de duração). Ao referi-los na sequência do 
artigo, utilizaremos a abreviação FC1 para a primeira série de reportagens e FC2 para a segunda.

7 No decorrer deste texto, o programa Globo Repórter será referido pela abreviatura GR.

8 Ao longo do texto optamos por utilizar o termo jornalismo, ao invés de telejornalismo, por entender que o primeiro se refere a uma linguagem específica que abrange o modo de construção de um telejornal.

${ }^{9}$ A autora chama a atenção para não se confundir a questão da novelização do telejornalismo com alguma forma de manipulação sobre os telespectadores, pois entende que a veracidade dos fatos é permanentemente esperada pelo público e não estaria comprometida por tal processo.

10 Segundo o ECA, as medidas de proteção são aplicáveis: I - por ação ou omissão da sociedade ou Estado; II - por falta, omissão ou abuso dos pais ou responsável; II - em razão de sua conduta (BRASIL, 1990).

${ }^{11} \mathrm{O}$ infotainment surgiu partir de dois contextos, o das engenharias da computação e da indústria automobilística (caracterizando as aplicações multimídia digitais em tempo real, que permitem o acesso a serviços de informação e entretenimento), e o das Ciências Sociais, especialmente na Comunicação. Refere-se ao embaralhamento entre informação e entretenimento - aqui entendido como "um valor das sociedades ocidentais contemporâneas que se organiza como indústria e se traduz por um conjunto de estratégias para atrair a atenção de seus consumidores" (Gomes, 2010, p. 204).

${ }^{12}$ Isto se evidencia em outras cenas presentes nos materiais da pesquisa, cuja análise figura em outro escrito. 